\title{
Desenvolvimento de materiais adsorventes de óleos a partir de resíduos do beneficiamento do café e sua aplicação na ração para aves
}

\author{
Development of oil adsorbent materials from the processing coffee waste and its \\ application in poultry feed
}

\section{OLIVEIRA, Lílian Karla ${ }^{1 *}$; CASTRO, Solange de Faria ${ }^{2}$; BERTECHINI, Antonio Gilberto $^{2}$; LIMA, Eduardo Machado Costa ${ }^{2}$; ESPÓSITO, Marcelo ${ }^{2}$; BIANCHI, Maria Lúcia ${ }^{3}$}

\footnotetext{
${ }^{1}$ Universidade Estadual Paulista, Instituto de Química, Araraquara, São Paulo, Brasil

${ }^{2}$ Universidade Federal de Lavras, Departamento de Zootecnia, Lavras, Minas Gerais, Brasil.

${ }^{3}$ Universidade Federal de Lavras, Departamento de Química, Lavras, Minas Gerais, Brasil.

*Endereço para correspondência: 1.koliveira@yahoo.com.br
}

RESUMO

O objetivo deste trabalho foi modificar quimicamente resíduos do beneficiamento do café (pergaminho), visando a obtenção de um produto mais hidrofóbico, testá-lo quanto ao seu poder adsorvente de óleo e utilizá-lo em formulações de rações para aves. Os resíduos foram analisados quanto a sua composição química-bromatológica e, posteriormente, acetilados com anidrido acético usando diferentes concentrações de $N$-bromossuccinimida, a temperatura de $120^{\circ} \mathrm{C}$ por 4 horas. A análise dos resíduos indicou altos teores de fibras. A acetilação possibilitou ganho de massa em todas as amostras estudadas. Nos testes de adsorção de óleo verificou-se aumento significativo na retenção de óleo dos materiais modificados, comprovando a hidrofobização. $\mathrm{O}$ material acetilado e com certa quantidade de óleo adsorvida foi chamado de OSoL (óleo sólido) sendo avaliado o seu valor nutricional em rações para aves, substituindo o óleo de soja. Nos ensaios metabólicos adotou-se o método de alimentação forcada, sendo determinados os valores de energia metabolizável verdadeira, energia metabolizável verdadeira corrigida para nitrogênio, coeficiente de digestibilidade da matéria seca, coeficiente de digestibilidade da proteína bruta e coeficiente de metabolizibilidade da energia metabolizável. Os tratamentos mostraram-se semelhantes estatisticamente, sendo, portanto, viável a inclusão do OSoL nas rações animais.

Palavras-chave: resíduos agroindustriais, modificação química, nutrição animal.

\section{SUMMARY}

The aim of this work was chemically modify lignocellulosic materials (processing coffee waste-parchment) in order to obtain a more hydrophobic material, test it as to its oil adsorbent capacity and use it in the formulation of poultry feed. The residues were analyzed for its chemical-bromatologic composition and subsequently acetylated with acetic anhydride using different concentrations of $\mathrm{N}$ bromosuccinimide (as catalyst) for 4 hours at $120^{\circ}$ C. Analysis of the parchment indicates high levels of fiber. The acetylation of this material promotes mass gain for all samples studied. An increase in the oil adsorption capacity was observed for all the modified materials, proving the hydrophobization. Acetylated material with adsorbed oil was called OSoL (solid oil) and replaced soybean oil in poultry diet. In metabolic experiments we adopted the method of forced feeding and determined the true metabolizable energy values, true metabolizable energy corrected for nitrogen, digestibility of dry matter, digestibility of crude protein and metabolizable energy coefficient of metabolizibility. The treatments were similar statistically; therefore, the inclusion of OSOL in poultry diet is viable.

Keywords: agro-industrial residues, chemical modification, animal nutrition. 


\section{INTRODUÇÃO}

O café é o segundo produto de maior comercialização no mundo, e o Brasil o seu maior produtor. A quantidade de resíduos gerados no beneficiamento do café ocorre na proporção de 1:1 em relação à produção, ou seja, para cada tonelada de café beneficiado, uma tonelada de resíduo é gerada. Esses resíduos, constituídos principalmente por materiais lignocelulósicos, vêm ganhando espaço cada vez maior porque além de representarem matéria prima de baixo custo e abundante também podem causar efeitos nocivos ao ambiente quando descartados de forma inadequada (JAYACHANDRA et al., 2011).

Resíduos agrícolas com elevados teores de fibra já são largamente estudados como matriz alimentícia para animais (BARROS et al., 2009; BERNARDINHO et al, 2009). No entanto, esses materiais apresentam a desvantagem de absorver água em grande quantidade, o que pode interferir na sua qualidade como fonte dos nutrientes. Uma das alternativas para contornar esse problema seria submetêlos às reações de modificação química, de forma a torná-los mais hidrofóbicos.

Além de melhorar a qualidade dos nutrientes em dietas para frangos de corte, esses resíduos modificados poderiam ser utilizados como um suporte para adsorção de óleos vegetais, comumente utilizados como fonte de alta energia na alimentação de aves. (SHIN et al. 2012). Assim, ao invés de se utilizar o óleo líquido na preparação das rações seriam utilizados resíduos modificados com óleo adsorvido (OSoL - óleo sólido). Este fato seria vantajoso já que existem dificuldades práticas e econômicas do uso de óleo líquido na preparação das rações.

A possibilidade de transformar esses óleos em ingredientes sólidos poderia contribuir para a redução dos custos de produção das rações e, consequentemente, diminuir o custo final de produção de frangos de corte. Dessa maneira, o presente trabalho foi realizado com o objetivo de utilizar os resíduos do beneficiamento do café (pergaminho) como matéria prima para produção de material hidrofóbico, sendo testado quanto a sua capacidade de adsorção de óleo vegetal. O produto obtido foi utilizado como ingrediente na ração para aves e seu desempenho avaliado.

\section{MATERIAL E MÉTODOS}

Os resíduos do café, pergaminho (PM), foram obtidos na fazenda da EPAMIG (Machado-MG). As amostras foram secas e moídas (40-60 mesh) e adequadamente armazenadas para posterior esterificação. Os materiais foram analisados quanto aos teores de matéria seca (MS), cinzas, fibra em detergente neutro (FDN), fibra em detergente ácido (FDA) e proteína bruta (PB), conforme procedimento descrito por Silva \& Queiroz (2002) e extrato etéreo (EE), de acordo com a metodologia proposta pelo Instituto Adolfo Lutz (2002).

Nas reações de acetilação, $20 \mathrm{~g}$ do material foram colocados em balão de fundo redondo, com capacidade para $1 \mathrm{~L}$, juntamente com $800 \mathrm{~mL}$ de anidrido acético e diferentes quantidades $(0,5$ e $0,2 \% \mathrm{~m} / \mathrm{v})$ de NBS ( $N$-bromossuccinimida). O conjunto foi acoplado a um condensador e levado para um banho de óleo a $120^{\circ} \mathrm{C}$, durante 4h. Após esse período, as amostras 
foram filtradas e lavadas com etanol e acetona para a retirada de resíduos de anidrido acético e de subprodutos, como o ácido acético. Para avaliar o ganho de massa após a acetilação, o material foi pesado antes e após a reação. $\mathrm{O}$ ganho em massa (GM) foi calculado de acordo com a Equação 1.

$$
\text { Equação 1: } G M(\%)=\left(\frac{m_{\text {material tratado }}-m_{\text {material não tratado }}}{m_{\text {material não tratado }}}\right) \times 100
$$

Foram obtidos espectros na região do infravermelho dos materiais produzidos utilizando-se pastilhas de $\mathrm{KBr}$ em um espectrofotômetro Digilab série Excalibur. As amostras foram analisadas quanto aos teores de carbono e de hidrogênio em um equipamento Flash EA série 1112, e o teor de oxigênio determinado por diferença.
Os cálculos de \% de ganho de carbono (\%CG) foram feitos de acordo com a Equação 2 em que \% GC é o ganho de carbono após a modificação; \% $\mathrm{C}_{\text {mod }}$ é o conteúdo de carbono modificado; \% $\mathrm{C}_{\text {nmod }}$ é o conteúdo de carbono não modificado.

$$
\text { Equação 2: } \% C G=\left(\frac{\% C_{\bmod }-\% C_{n \bmod }}{\% C_{n \bmod }}\right) \times 100
$$

As amostras foram testadas quanto à capacidade de adsorção de óleo em diversas temperaturas. Para os testes, foram adicionados $0,5 \mathrm{~g}$ do material acetilado e $20 \mathrm{~mL}$ de óleo. Após a adsorção, o material foi filtrado $\mathrm{e}$ pesado.

Nos testes de inclusão em rações para aves, foi utilizado o "OSoL" do pergaminho, acetilado com $0,2 \%$ de NBS. 32 galos Leghorn com 21 meses de idade e peso médio de $2160 \pm 320 \mathrm{~g}$, cecectomizados por meio de laparotomia abdominal e anestesia local, foram distribuídos em um delineamento inteiramente casualizado com oito repetições para cada tratamento, em que cada ave representava uma unidade experimental. Foram fornecidos $30 \mathrm{~g}$ de alimento, duas vezes ao dia e, para evitar regurgitações, foi utilizado um funil-sonda introduzido via esôfago até o papo.

As rações experimentais foram formuladas à base de milho e farelo de soja (Tabela 1). Os tratamentos foram constituídos de um controle positivo $\mathrm{CP}$, segundo recomendações de Rostagno et al. (2011); um controle negativo - CN (redução de $0,66 \%$ de óleo do CP); uma dieta com a inclusão do "OSoL" e outra apenas com a inclusão do resíduo (pergaminho) não modificado.

No ensaio metabólico, foi adotada a metodologia de alimentação forçada, descrita por Sibbald (1976), e os valores energéticos foram determinados com a utilização dos procedimentos convencionais de coleta total de excretas. Estas foram armazenadas em freezer, à temperatura de $-5{ }^{\circ} \mathrm{C}$, até $\mathrm{o}$ final do período de coleta. Ao final do 
período de coleta (3 dias), as excretas foram pesadas, homogeneizadas e liofilizadas a $-70^{\circ} \mathrm{C}$ por 72 horas, para posterior realização das análises de matéria seca $(\mathrm{MS})$, nitrogênio $(\mathrm{N}) \mathrm{e}$ energia bruta (EB).

Determinaram-se os valores de energia metabolizável verdadeira (EMV) e corrigida para nitrogênio (EMVn) e os coeficientes de digestibilidade aparente da matéria seca (CDMS), de proteína bruta (CDPB) e coeficiente de metabolizibilidade de energia metabolizável (CMEM). Os resultados de EMV, EMVn, CDMS, CDPB e CMEM foram submetidos a análises de variância, utilizando $o$ pacote computacional "Sistemas para Análises de Variância" (SISVAR), segundo Ferreira (2010). Os tratamentos foram comparados pelo teste de Tukey e contrastes ortogonais, a 5\% de probabilidade.

Tabela 1. Composição percentual e níveis nutricionais calculados das rações experimentais

\begin{tabular}{|c|c|c|c|c|}
\hline Ingredientes & $\begin{array}{l}\mathrm{CP} \\
(\%)\end{array}$ & $\begin{array}{l}\mathrm{CN} \\
(\%)\end{array}$ & $\begin{array}{c}\mathrm{CP}+\mathrm{OSoL} \\
(\%)\end{array}$ & $\begin{array}{c}\mathrm{CP}+ \\
\text { pergaminho }(\%)\end{array}$ \\
\hline Milho & 60,59 & 60,59 & 60,59 & 60,59 \\
\hline Farelo de soja & 30,98 & 30,98 & 30,98 & 30,98 \\
\hline Óleo de soja & 4,58 & 3,05 & -- & 4,58 \\
\hline "OSoL" " & -- & -- & 4,58 & -- \\
\hline Fosfato bicálcico 24/18 & 1,92 & 1,92 & 1,92 & 1,92 \\
\hline Calcário calcítico & 1,05 & 1,05 & 1,05 & 1,05 \\
\hline Sal comum & 0,38 & 0,38 & 0,38 & 0,38 \\
\hline Suplemento mineral ${ }^{1}$ & 0,10 & 0,10 & 0,10 & 0,10 \\
\hline Suplemento vitamínico ${ }^{2}$ & 0,10 & 0,10 & 0,10 & 0,10 \\
\hline DL-metionina 99\% & 0,17 & 0,17 & 0,17 & 0,17 \\
\hline L-lisina $78 \%$ & 0,04 & 0,04 & 0,04 & 0,04 \\
\hline Salinomicina $12 \%$ & 0,05 & 0,05 & 0,05 & 0,05 \\
\hline Sulfato colistina $8 \%$ & 0,01 & 0,01 & 0,01 & 0,01 \\
\hline Bacitracina de zinco $15 \%$ & 0,03 & 0,03 & 0,03 & 0,03 \\
\hline Cloreto de colina $70 \%$ & 0,04 & 0,04 & 0,04 & 0,04 \\
\hline Inerte & -- & 1,53 & -- & -- \\
\hline Pergaminho não modificado & -- & -- & -- & 1,53 \\
\hline Total & 100,00 & 100,00 & 100,00 & 100,00 \\
\hline \multicolumn{5}{|l|}{ Composição calculada } \\
\hline Energia metabolizável (kcal/kg) & 3.150 & 3.000 & 3.150 & 3.150 \\
\hline Proteína bruta $(\%)$ & 21,34 & 21,34 & 21,34 & 21,34 \\
\hline Cálcio $(\%)$ & 0,95 & 0,95 & 0,95 & 0,95 \\
\hline Fósforo disponível (\%) & 0,45 & 0,45 & 0,45 & 0,45 \\
\hline Sódio $(\%)$ & 0,17 & 0,17 & 0,17 & 0,17 \\
\hline
\end{tabular}

${ }^{\top}$ Suplemento mineral (por kg de ração): ferro, $80 \mathrm{mg}$; zinco, $90 \mathrm{mg}$; iodo, $1 \mathrm{mg}$; selênio, 0,25mg; manganês, 60mg; cobre, $10 \mathrm{mg}$. ${ }^{2}$ Suplemento vitamínico (por kg de ração): Vitamina A, 8.000UI; vitamina $\mathrm{D}_{3}$, 2.000UI; vitamina E, 30UI; vitamina $K_{3}, 2,5 \mathrm{mg}$; vitamina $B_{1}, 2,4 \mathrm{mg}$; vitamina $B_{2}, 4,0 \mathrm{mg}$; vitamina $B_{6}$, 2,0mg; vitamina $\mathrm{B}_{12}, 0,014 \mathrm{mg}$; biotina, $0,060 \mathrm{mg}$; colina, $250 \mathrm{mg}$. $\mathrm{CP}=$ controle positivo. $\mathrm{CN}=$ controle negativo. 


\section{RESULTADOS E DISCUSSÃO}

De acordo com as análises químicas e bromatológicas (Tabela 2) do pergaminho (PM), observou-se que o mesmo apresenta teores elevados de MS (superior a 90\%). Com isso constatou-se que este material é considerado favorável ao armazenamento, possível de ser conservado por um período de tempo mais longo, visto que um menor teor de água diminui a atividade microbiana. A maior fração do PM é composta de fibras.

Tabela 2. Análises químicas e bromatológicas do pergaminho

\begin{tabular}{lc}
\hline Composição & $\%$ \\
\hline Matéria seca & 91,5 \\
Extrato etéreo & 3,0 \\
Fibra em detergente neutro & 90,2 \\
Fibra em detergente ácido & 74,4 \\
Proteína bruta & 4,1 \\
Cinzas & 1,3 \\
Hemicelulose & $34,8^{1}$ \\
Celulose & $41,2^{1}$ \\
Lignina & $22,0^{1}$ \\
Extrativo não nitrogenado & $7,0^{1}$ \\
${ }^{1}$ Brum ( 2007). &
\end{tabular}

Verificou-se que o resíduo é constituído de um alto teor de fibras (celulose, hemiceluloses e lignina), o que já era esperado. Segundo Bauer et al. (2008), entre os constituintes da parede celular, a celulose e as hemiceluloses são, normalmente, a fonte de substrato disponível na nutrição animal. No entanto, a presença de lignina na parede celular influencia a digestibilidade dessas substâncias. Os resultados obtidos na análise bromatólogica foram similares aos encontrados por Vilela
(2001): MS (95,86\%), FDN (89,39\%), FDA $(79,12 \%)$ e PB $(4,76 \%)$.

Na reação de acetilação do pergaminho com anidrido acético, os hidrogênios $(\mathrm{H})$ dos grupos hidroxílicos $(\mathrm{OH})$ são substituídos por grupos acetila, que apresentam maior massa molecular. Assim, os materiais modificados apresentaram maior massa que os não modificados (Tabela 3).

Tabela 3. Porcentagem de ganho de massa (GM) após a acetilação com diferentes \% de NBS

\begin{tabular}{ccc}
\hline Reação & NBS (\%) & GM (\%) \\
\hline 1 & 0,5 & 15,40 \\
2 & 0,2 & 12,20 \\
\hline$\%$ NBS: $N$-bromossuccinimida (m/v).
\end{tabular}

Observou-se aumento $(\mathrm{P}<0,05)$ na taxa de ganho de massa nas reações de acetilação (Tabela 3). Quando as reações foram comparadas, verificou-se que o aumento na proporção de NBS não alterou significativamente a taxa de ganho de massa. O mesmo foi observado por $\mathrm{Xu}$ et al. (2010), que acetilaram hemiceluloses (galactoglucomananas) com anidrido acético e piridina, em diferentes concentrações, e verificaram que o aumento da quantidade de catalisador não elevou o grau de acetilação de seus compostos.

Apesar do ganho de massa ter evidenciado a troca dos grupos hidroxílicos por grupos acetilas (mais pesados), esse resultado não confirma a presença de ligação química entre o composto e a parede celular. Dessa forma, outras análises como espectroscopia na região do infravermelho (Figura 1) e análise elementar (Tabela 4) foram realizadas para confirmar a ligação. 
Verificou-se a ocorrência das reações de esterificação nos tratamentos pela presença de bandas características de ligações ésteres: em $1.750 \mathrm{~cm}^{-1}$, referente ao estiramento de grupos carbonila $(\mathrm{C}=\mathrm{O})$; em $1.374 \mathrm{~cm}^{-1}$, referente às ligações de $\mathrm{C}-\mathrm{H}$ do grupo $\mathrm{CH}_{3}$ da acetila; e em $1.237 \mathrm{~cm}^{-1}$, referente à ligação $\mathrm{C}-\mathrm{O}$ do grupo acetila. A diminuição da intensidade da banda em $3.400 \mathrm{~cm}^{-1}$ pode ser atribuída à redução da quantidade de grupos hidroxílicos, o que sugere a ocorrência da acetilação, visto que os grupos - $\mathrm{OH}$ são substituídos por grupos acetila (REDDY et al. 2011). Em nenhum dos espectros verificou-se bandas na região de $1.840-1.760 \mathrm{~cm}^{-1}$ e $1.700 \mathrm{~cm}^{-1}$, o que indica a ausência de anidrido acético e ácido acético nos materiais (Figura 1).

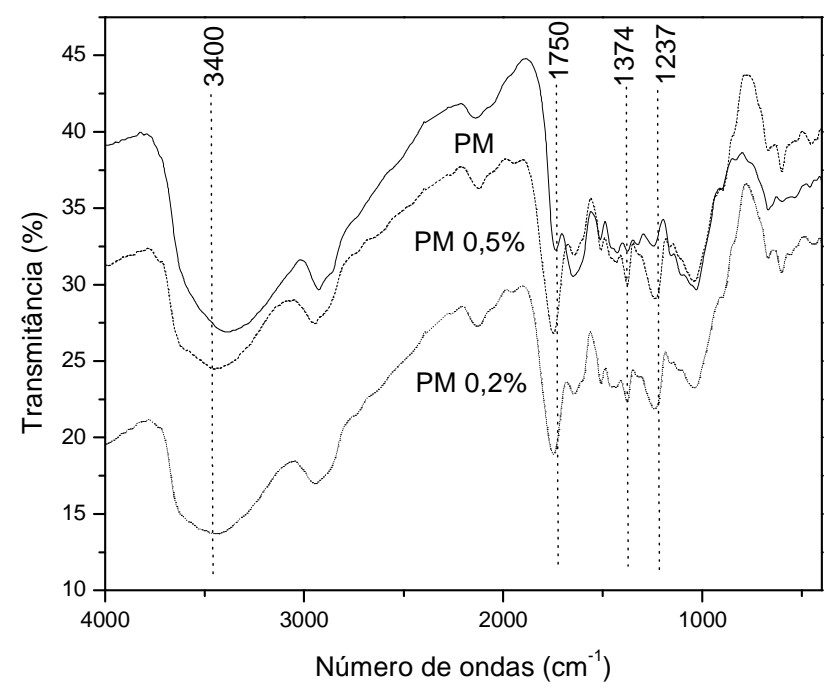

Figura 1. Espectros na região do infravermelho médio do pergaminho não modificado (PM) e modificado (PM 0,2\% e PM 0,5\%)

A análise elementar dos materiais foi feita para verificar o ganho de carbono destes após as reações de acetilação, uma vez que, durante esse processo, os grupos -OH são trocados por acetila (Tabela 4). Observou-se ganho de carbono de aproximadamente $9 \%$ após as reações de acetilação. Quando as reações 1 e 2 foram comparadas, verificou-se o aumento da quantidade de NBS utilizado (de $0,2 \%$ para $0,5 \%$ ) não causou efeito significativo na \% GC. Isso sugere que o número máximo de esterificações dos grupos hidroxílicos acessíveis deve ter sido alcançado.

A análise dos dados referentes à adsorção de óleo (em diferentes temperaturas) no material não acetilado e acetilado (Tabela 5) mostrou que a hidrofobicidade dos materiais lignocelulósicos está diretamente ligada às hidroxilas presentes na celulose, hemiceluloses e lignina. Com as reações de acetilação, constatou-se que a hidrofobicidade aumenta e faz surgir um novo material com características lipofílicas. 
Rev. Bras. Saúde Prod. Anim., Salvador, v.13, n.4, p.902-911 out./dez., 2012 http://www.rbspa.ufba.br ISSN 15199940

Tabela 4. Análise elementar do pergaminho e do pergaminho modificado por diferentes reações

\begin{tabular}{lccccc}
\hline Reação & NBS (\%) & $\% \mathrm{C}$ & $\% \mathrm{H}$ & $\% \mathrm{O}^{*}$ & $\% \mathrm{GC}$ \\
\hline 1 & 0,5 & 48,3 & 5,4 & 46,1 & 9,8 \\
2 & 0,2 & 47,8 & 5,4 & 46,5 & 8,6 \\
$\mathrm{PM}^{1}$ & - & 44,0 & 5,4 & 49,9 & - \\
\hline *\%O=obtido por diferença; ${ }^{1}$ Pergaminho não modificado. & & &
\end{tabular}

*\% $\mathrm{O}=$ obtido por diferença; ${ }^{1}$ Pergaminho não modificado.

Tabela 5. Adsorções de óleo no pergaminho (PM) modificado e PM não modificado

\begin{tabular}{lccc}
\hline \multirow{2}{*}{$\mathrm{T}\left({ }^{\circ} \mathrm{C}\right)$} & PM & PM 0,2\% NBS & PM 0,5\% NBS \\
\cline { 2 - 4 } & g de óleo/g material & g de óleo/g material & g de óleo/g material \\
\hline 25 & 1,21 & 1,59 & 1,66 \\
40 & 1,19 & 1,36 & 1,72 \\
50 & 1,19 & 1,36 & 1,69 \\
60 & 1,04 & 1,57 & 1,59 \\
70 & 1,15 & 1,34 & 1,49 \\
80 & 1,01 & 1,26 & 1,59 \\
\hline
\end{tabular}

Os materiais modificados apresentaram um aumento na adsorção de óleo, se comparados ao pergaminho não modificado, o que comprova a ocorrência da hidrofobização (Tabela 5). Observouse que as adsorções no pergaminho modificado e não modificado não são significativamente afetadas com 0 aumento da temperatura.

Após a caracterização dos materiais acetilados, foi feita a escolha do material para o preparo do "OSoL" (PM + óleo adsorvido). O PM 0,2\% NBS foi usado, já que não apresentou diferenças significativas, quando comparado ao PM $0,5 \%$ NBS. Como não houve variância significativa nas adsorções de óleo com o aumento da temperatura os "OSoL's" foram preparados a $25^{\circ} \mathrm{C}$ (temperatura ambiente).

A avaliação do desempenho das formulações utilizando ou não o "OSol" mostrou diferença $(\mathrm{P}<0,05)$ para a EMVn entre os tratamentos (Tabela 6), e o tratamento controle positivo (CP) e $\mathrm{CP}+$ "OSoL" obtiveram valores superiores aos demais. Embora tenha havido diferença significativa $(\mathrm{P}<0,05)$ entre os tratamentos controle positivo e negativo $(\mathrm{CN})$, esse resultado pode ser explicado pela redução no nível de óleo da ração do $\mathrm{CN}(4,58 \%$ para $3,05 \%)$.

Quando realizados os contrastes para EMVn, percebeu-se que apenas o tratamento controle positivo se mostrou superior $(\mathrm{P}<0,05)$ aos demais. Também verificou-se que não houve alteração $(\mathrm{P}>0,05)$ dos valores de EMV e EMVn, quando utilizado o óleo diretamente na ração ou o "OSoL", o que comprova sua eficiência para a inclusão de óleo na ração. Não se pode afirmar o mesmo a respeito do uso apenas do pergaminho não modificado, que foi inferior ao controle positivo e semelhante ao controle negativo, mesmo com a inclusão de óleo semelhante ao controle positivo. Os valores de EMV foram superiores aos de EMVn, o que pode ser atribuído às maiores perdas de nitrogênio endógeno pelas aves em jejum (FRANCHESCH et al., 2002). 
Rev. Bras. Saúde Prod. Anim., Salvador, v.13, n.4, p.902-911 out./dez., 2012 http://www.rbspa.ufba.br ISSN 15199940

Tabela 6. Valores de energia metabolizável (EM), coeficientes de digestibilidade (CD) e metabolização (CM), em base de matéria seca

\begin{tabular}{|c|c|c|c|c|c|}
\hline Tratamentos & $\begin{array}{c}\text { EMV } \\
(\mathrm{kcal} / \mathrm{kg})\end{array}$ & $\begin{array}{c}\text { EMVn } \\
(\mathrm{kcal} / \mathrm{kg})\end{array}$ & $\begin{array}{c}\text { CDMS } \\
(\%)\end{array}$ & $\begin{array}{c}\text { CDPB } \\
(\%)\end{array}$ & $\begin{array}{l}\text { CMEM } \\
(\%)\end{array}$ \\
\hline Controle Positivo (CP) & $3.943^{\mathrm{a}}$ & $3.593^{\mathrm{a}}$ & $86,65^{\mathrm{b}}$ & $40,06^{\mathrm{bc}}$ & $96,84^{\mathrm{a}}$ \\
\hline Controle Negativo (CN) & $3.796^{\mathrm{b}}$ & $3.478^{\mathrm{bc}}$ & $90,41^{\mathrm{a}}$ & $54,78^{\mathrm{ab}}$ & $97,83^{\mathrm{a}}$ \\
\hline $\mathrm{CP}+" \mathrm{OSOL} "$ & $3.915^{\mathrm{a}}$ & $3.514^{\mathrm{b}}$ & $89,38^{\mathrm{a}}$ & $51,78^{\mathrm{b}}$ & $97,56^{\mathrm{a}}$ \\
\hline $\mathrm{CP}+\mathrm{PM}$ & $3.769^{\mathrm{b}}$ & $3.463^{\mathrm{c}}$ & $90,76^{\mathrm{a}}$ & $64,51^{\mathrm{a}}$ & $94,14^{\mathrm{b}}$ \\
\hline Média & 3.856 & 3.512 & 89,30 & 52,78 & 96,59 \\
\hline Coef. Variação, \% & 2,44 & 1,60 & 3,66 & 27,59 & 2,52 \\
\hline Probabilidade, $\mathrm{P} \leq$ & $* * *$ & $* * *$ & $* *$ & $* * *$ & $* * *$ \\
\hline \multicolumn{6}{|c|}{ Probabilidade para contrastes, $\mathrm{P} \leq$} \\
\hline $\begin{array}{l}\text { Sem resíduos vs com } \\
\text { resíduos }\end{array}$ & $* * *$ & $* * *$ & NS & NS & NS \\
\hline $\mathrm{CP}$ vs $\mathrm{CN}$ & $* * *$ & $* * *$ & NS & *** & NS \\
\hline $\mathrm{CP}$ vs $\mathrm{CP}+\mathrm{OSoL}$ & NS & $* * *$ & NS & $* * *$ & NS \\
\hline $\mathrm{CP}$ vs $\mathrm{CP}+\mathrm{PM}$ & $* * *$ & $* * *$ & NS & $* * *$ & $* * *$ \\
\hline
\end{tabular}

Médias com letras minúsculas distintas na coluna diferem estatisticamente $(\mathrm{P}<0,05)$ pelo teste de Tukey. NS = não significativo. $* * \mathrm{P}<0.01 . * * \mathrm{P}<0.001$

$\mathrm{EMV}=$ energia metabolizável verdadeira; $\mathrm{EMVn}=$ energia metabolizável verdadeira corrigida para nitrogênio; $\mathrm{CDMS}=$ coeficiente de digestibilidade da matéria seca; $\mathrm{CDPB}=$ coeficiente de digestibilidade da proteína bruta; $\mathrm{CMEB}=$ coeficiente de metabolização da energia bruta.

Freitas et al. (2005), ao estudarem o efeito do processamento de soja integral sobre a energia metabolizável, analisaram uma mistura de farelo de soja e óleo de soja e obtiveram valores de $4.143 \mathrm{kcal} / \mathrm{kg}$ para EMV e $3.527 \mathrm{kcal} / \mathrm{kg}$ EMVn, próximos aos encontrados neste trabalho, cujo experimento utilizou óleo de soja adsorvido no PM modificado.

$\mathrm{Na}$ análise dos valores médios obtidos para as digestibilidades dos nutrientes (Tabela 6), observaram-se efeitos similares para os tratamentos $\mathrm{CP}, \mathrm{CN}$ e $\mathrm{CP}+$ +OSoL". Os valores de probabilidade dos contrastes para $\mathrm{o}$ CDMS mostraram que não houve variância significativa entre os tratamentos $(\mathrm{P}>0,05)$. Já nos contrastes do CDPB, foram observadas diferenças significativas nos tratamentos $\mathrm{CP}+$ "OSoL" e CP + PM quando comparados ao tratamento $\mathrm{CP}(\mathrm{P}<0,05)$. Esses dados permitem afirmar, portanto, que $\mathrm{O}$ aproveitamento de proteína bruta do tratamento $\mathrm{CN}$ foi semelhante ao controle positivo. Ao se observarem os valores de contrastes obtidos para a CMEM, percebeu-se que os tratamentos $\mathrm{CN}$ e $\mathrm{CP}+$ +OSoL" mostraram-se idênticos ao tratamento $\mathrm{CP}$.

De acordo com os resultados encontrados, o "OSoL" pode ser adicionado às rações sem que haja diferença significativa nos valores de energia metabolizável, uma vez que se assemelham estatisticamente aos valores encontrados para o controle. $\mathrm{O}$ "OSoL" (óleo sólido = resíduo modificado + óleo adsorvido) é um material sólido que contém grande quantidade de óleo adsorvido e pode ser utilizado no preparo de rações para aves em substituição do óleo líquido. A troca do óleo líquido pelo "OSoL" na preparação das rações seria vantajosa, ao se considerar que a adição de líquidos no processo é mais onerosa e necessita de atenção especial.

$\mathrm{O}$ desenvolvimento da pesquisa mostrou que o pergaminho, resíduo do 
beneficiamento do café, quando modificado quimicamente, produz um material de valor econômico que pode ser utilizado na preparação de ração para aves, de forma a contribuir para redução dos custos de produção de frangos de corte. Os testes realizados com o "OSoL" constataram que esse produto pode ser adicionado às rações de aves em substituição ao óleo líquido, sem que haja diferenças significativas nos valores de energia metabolizável ou redução na digestibilidade dos nutrientes da dieta.

\section{REFERÊNCIAS}

BAUER, M.O.;GOMIDE, J.A.; SILVA, E.A.M.; REGAZZI, A.J.; CHICHORRO, J.F. Características anatômicas e valor nutritivo de quatro gramíneas predominantes em pastagem natural de Vicosa, MG. Revista

Brasileira de Zootecnia, v.37, n.1, p.917, 2008.

BARROS, R.C.; ROCHA JÚNIOR, V.R.; SILVA, F.V.; ALVES, D.D.; SALES, E.C.; FRANCO, M.O.; REIS, S.T.; SOUZA, A.S. Cana de açúcar ou bagaço de cana amonizado com uréia em substituição à silagem de sorgo para bovinos de corte confinados. Revista

Brasileira de Saúde e Produção Animal [Online], v.10, n.2, p.278-292, 2009.

BERNARDINO, F.S.; GARCIA, R.; TONUCCI, R.G.; ROCHA, F.C.; FILHO, S.C.V.; PEREIRA, O.G. Consumo e digestibilidade e nutrientes de silagens de capim elefante com casca de café, por ovinos. Revista Brasileira de Saúde e Produção Animal [Online], v.10, n.2, p.460-469, 2009.
BRUM, S.S. Caracterização e modificação química de resíduos sólidos do beneficiamento do café para produção de novos materiais. 2007. 138p. Dissertação (Mestrado em Agroquímica) - Universidade Federal de Lavras, Lavras.

FERREIRA, D.F. Sistema de análises de variância para dados balanceados: SISVAR 4.1. Lavras: Universidade Federal de Lavras, 2010.

FRANCHESCH, M.; BERNARD, K.; MCNAB, J.M. Comparison of two direct bioassays using 3-week-old broilers to measure the metabolizable energy of diets containing cereals high in fiber: differences between true and apparent metabolizable energy values. British Poultry Science, v.43, n.4, p.580-587, 2002.

FREITAS, E.R.; DAHLKE, F.; SANTOS, F.R.; BARBOSA, N.A.A. Efeito do processamento da soja integral sobre a energia metabolizavel e a digestibilidade dos aminoacidos para aves. Revista Brasileira de Zootecnia, v.34, n.6, p.1938-1949, 2005.

INSTITUTO ADOLFO LUTZ. Normas analíticas: Métodos químicos e físicos para análise de alimentos. 4.ed. São Paulo, 2002. 25p.

Jayachandra, T.; Venugopal, C.; Anu Appaiah, K.A. Utilization of phytotoxic agro waste-coffee cherry husk through pretreatment by the ascomycetes fungi Mycotypha for biomethanation. Energy for Sustainable Development, v.15, p104-108, 2011.

REDDY, N.; HU, C.; YAN, K.; YANG, Y. Acetylation of corn distillers dried grains. Applied Energy, v.88, p.16641670, 2011. 
ROSTAGNO, H.S. Tabelas brasileiras para aves e suínos: composição de alimentos e exigências nutricionais. 3.ed, Viçosa, MG: Universidade Federal de Viçosa, 2011. 252p.

SHIN, D.; CHOI, S.H.; GO, G.; PARK, J.H.; NARCISO-GAYTAN, C.; MORGAN, C.A.; SMITH, S.B.; SANCHEZ-PLATA, M.X.; RUIZFERIA, C.A. Effects of dietary combination of n-3 and n-9 fatty acids on the deposition of linoleic and arachidonic acid in broiler chicken meats. Poultry Science, v.91, p.10091017, 2012.

SIBBALD, I.R. A bioassay for true metabolizable energy in feedingstuffs. Poultry Science, v.55, n.1, p.303-308, 1976.
SILVA, D.J.; QUEIROZ, A.C. Análise de alimentos: métodos químicos e biológicos. 3.ed. Viçosa: Universidade Federal de Viçosa, 2002. 235p.

VILELA, F.G. Uso da casca de cafe melosa em diferentes niveis na alimentacao de novilhos confinados. Ciência Agrotecnologia, v.25, n.1, p.198-205, 2001.

XU, C.; LEPPANEN, A.S.; EKLUND, P.; HOLMLUND, P.; SJOHOLM, R.; SUNDBERG, K.; WILFOR, S. Acetylation and characterization of spruce (Picea abies) galactoglucomannans. Carbohydrate Research, v.345, p.810-816, 2010.

Data de recebimento: 05/01/2012

Data de aprovação: 23/10/2012 